\title{
Phytochemical and Biological Studies of Bark Extract of Miliusa velutina (Dunal) Hook. f. \& Thomson
}

\author{
Titumeer Al Fahad, Md. Ruhul Kuddus and Choudhury M. Hasan
}

Phytochemical Research Laboratory, Department of Pharmaceutical Chemistry

Faculty of Pharmacy, University of Dhaka, Dhaka-1000, Bangladesh

(Received: July 07, 2020; Accepted: November 15. 2020; Published (web): December 10, 2020)

\begin{abstract}
The main objective of the current research was phytochemical and biological studies of the stem bark of Miliusa velutina (Dunal) Hook. f. \& Thomson (Annonaceae). Four purified compounds i.e., friedelin, lupeol, $\beta$ sitosterone and caffeic acid were isolated by repeated chromatographic separation and purification of M. velutina. The compounds were identified by analysis of NMR spectral data. The crude dichloromethane extract of stem bark of M. velutina (DEMV) along with its Kupchan partitionates i.e., petroleum ether (PESF), ethyl acetate (EASF), chloroform (CSF) and aqueous (AQSF) soluble fraction were screened for antioxidant, cytotoxic, thrombolytic and antibacterial activities. During the antioxidant activity assay, the AQSF revealed maximum activity with $\mathrm{IC}_{50}$ value of $71.67 \mu \mathrm{g} / \mathrm{ml}$. The cytotoxicity of plant samples was determined by brine shrimp lethality bioassay, where the maximum cytotoxic activity has been observed for EASF $\left(\mathrm{LC}_{90}=9.01 \mu \mathrm{g} / \mathrm{ml}\right)$. In the thrombolytic activity test, the crude dichloromethane extract demonstrated significant efficacy with $46.27 \%$ inhibition of clot lysis. In antibacterial screening, the CSF exhibited noticeable inhibitory activity against Shigella boydii with the zone of inhibition $15 \mathrm{~mm}$ compared to the standard ciprofloxacin (zone of inhibition $=47 \mathrm{~mm}$ ).
\end{abstract}

Key words: Miliusa velutina, Friedelin, Lupeol, $\beta$-sitosterone, Caffeic acid, Antioxidant, Cytotoxic, Thrombolytic, Antimicrobial.

\section{INTRODUCTION}

Medicinal plants are a valuable source of bioactive molecules with therapeutic potential, and plant-based systems continue to play a pivotal role in maintaining human health. ${ }^{1}$ According to the World Health Organization (WHO) data, amongst the total population, $65 \%$ of people predominately depend upon traditional and plant-oriented medicines in their basic treatment. ${ }^{1}$ Although the global demand of plant-based medicine is rising day by day, the literature survey reveals that only $1 \%$ of them has been identified through scientific investigations and accepted for commercial uses. ${ }^{2}$ Therefore, the present studies were designed to characterize the secondary metabolites isolated from the stem bark of $M$. velutina. ${ }^{3}$ Besides, the biological investigations were also performed to assess the rationale of its use in traditional medicines.

Correspondence to: Choudhury M. Hasan

E-mail: cmhasan@gmail.com

Dhaka Univ. J. Pharm. Sci. 19(2): 125-131, 2020 (December) DOI: https://doi.org/10.3329/dujps.v19i2.50627
Miliusa velutina (Dunal) Hook. f. \& Thomson (Family: Annonaceae; Bengali name: Gandhagajari) is a deciduous tree $(8-11 \mathrm{~m}$ in height), which is distributed throughout the regions of Bangladesh, India, China, Malaysia. ${ }^{3}$ The genus Miliusa consists of approximately 40 species. But very few species have been studied to a significant extent. The essential oil of $M$. tomentosa exhibited pain-relieving property. ${ }^{4}$ Bioactive alkaloids such as 10methoxyliriodenine and 10-hydroxyliriodenine isolated from M. cf. banacea showed toxicity against DNA repair. ${ }^{5}$ The plant also contains cytotoxic acetogenin $^{6}$, an aporphine alkaloid, (+)-isocorydine $\alpha-N$-oxide $^{7}$ and four other alkaloids, reticuline, liriodenine and norcorydine. ${ }^{3,7}$ Recently, homogentisic acid derivatives, miliusanal, miliusanones $^{8}$, and bicyclic lactones ${ }^{9}$ named velutinones $\mathrm{A}-\mathrm{H}$ isolated from this plant have been shown to display antimalarial activity and toxicity against the cancer cell lines. ${ }^{8,9}$ 
Although several researchers have worked on the isolation of secondary metabolites from M. velutina, a few articles are published based on its pharmacological properties. $^{6-9}$ Therefore, in continuation of our previous work, ${ }^{10-12}$ we investigated the stem bark extract of M. velutina to isolate and characterize secondary metabolites and subsequent evaluation of antioxidant, cytotoxic, thrombolytic and antimicrobial properties of its extractives.

\section{MATERIALS AND METHODS}

General experimental procedures. ${ }^{1} \mathrm{H}$ NMR spectra were recorded in $\mathrm{CDCl}_{3}$ on Bruker $400 \mathrm{MHz}$ NMR. The chemical shifts are reported in ppm with respect to TMS. Preparative TLCs were carried out over silica gel $60 \mathrm{~F}_{254}$ coated glass plates, and $1 \%$ vanillin-sulfuric acid reagent was used to detect the compounds.

Collection and extraction of plant sample. Stem bark of $M$. velutina was collected from the Bhawal National Park, Gazipur, in January 2017. The plant was taxonomically identified in Bangladesh National Herbarium, Dhaka, Bangladesh where a voucher specimen has been deposited with accession No. DACB-28061. The dust-free, sun-dried plant samples were pulverized and macerated in $3.0 \mathrm{~L}$ dichloromethane at room temperature for 15 days. Whatman No. 1 filter paper was used to filter the mixture. The filtrate was concentrated to dryness with a rotary evaporator. The concentrated crude extract was subjected for modified Kupchan partitioning ${ }^{13}$ protocol into petroleum ether, ethyl acetate, chloroform and aqueous fractions.

Isolation of chemical constituents. For rapid fractionation, the crude dichloromethane extract of stem bark of M. velutina was fractionated by vacuum liquid chromatographic (VLC) tehnique ${ }^{14}$ utilizing silica gel $60 \mathrm{H}$ and petroleum ether, petroleum etherethyl acetate, ethyl acetate-methanol in order of increasing polarities. This provided thirty two VLC fractions. Following TLC screening of VLC fractions, two compounds, i.e., compound MV-1 and MV-2 were isolated from the different VLC fractions
9 and 14. On the other hand, VLC fraction 16 was subjected for gel permeation chromatography over lipophilic Sephadex (LH-20). Preparative TLC of column fractions 4-7 gave compound MV-3, which is a mixture of two compounds (MV-3a and MV-3b).

Antioxidant activity. The antioxidant potential of the plant samples in methanol solution $(2 \mathrm{ml})$ was screened by a commonly used DPPH free radical scavenging assay method. ${ }^{15}$

Cytotoxic activity. Brine shrimp lethality bioassay ${ }^{16,17}$ was carried out to evaluate the cytotoxic activity of the test samples. In this rapid bioassay, vincristine sulfate (VS) and dimethylsulfoxide (DMSO) were used as a positive and negative control, respectively.

In vitro thrombolytic activity. The in vitro assay method described by Prasad et al. ${ }^{18}$ was used to evaluate the efficacy of the plant samples as the thrombolytic agents. In this experiment, streptokinase (SK) was used as the reference standard and distilled water as a negative control.

Antimicrobial activity. The most common disc diffusion method ${ }^{19,20}$ was adopted to evaluate the antimicrobial activity of the plant samples. Here, antibacterial drug ciprofloxacin $(30 \mu \mathrm{g})$ and the antifungal agent fluconazole $(30 \mu \mathrm{g})$ were used as the controls agents.

Properties of isolated compounds. Friedelin (MV-1): White solid crystals; ${ }^{1} \mathrm{H}$ NMR $(400 \mathrm{MHz}$, $\left.\mathrm{CDCl}_{3}\right): \delta 2.43\left(1 \mathrm{H}, \mathrm{m}, \mathrm{H}_{\mathrm{b}}-2\right), 2.29\left(1 \mathrm{H}, \mathrm{m}, \mathrm{H}_{\mathrm{a}}-2\right)$, $1.70\left(1 \mathrm{H}, \mathrm{m}, \mathrm{H}_{\mathrm{a}}-1\right), 1.20(3 \mathrm{H}, \mathrm{s}, \mathrm{H}-28), 1.07(3 \mathrm{H}, \mathrm{s}$, H-27), 1.03 (3H, s, H-26), 1.02 (3H, s, H-29), 0.97 $(3 \mathrm{H}, \mathrm{s}, \mathrm{H}-30), 0.90$ (3H, d, $J=6.4 \mathrm{~Hz}, \mathrm{H}-23), 0.89$ (3H, s, H-25), 0.75 (3H, s, H-24).

Lupeol (MV-2): White amorphous solid; ${ }^{1} \mathrm{H}$ NMR (400 MHz, $\left.\mathrm{CDCl}_{3}\right): \delta 4.71$ and $4.59(1 \mathrm{H}$, br. s each, H-29), 3.21 (1H, m, H-3), $2.40(1 \mathrm{H}, \mathrm{m}, \mathrm{H}-19)$, 1.70 (3H, s, H-30), 1.05 (3H, s, H-26), 0.99 (3H, s, H-23), 0.97 (3H, s, H-27), 0.85 (3H, s, H-25), 0.81 $(3 \mathrm{H}, \mathrm{s}, \mathrm{H}-28), 0.78$ (3H, s, H-24).

$\beta$-sitosterone (MV-3a): Yellowish solid; ${ }^{1} \mathrm{H}$ NMR $\left(400 \mathrm{MHz}, \mathrm{CDCl}_{3}\right): \delta 5.75(1 \mathrm{H}$, br. s, H-6), $1.20(3 \mathrm{H}, \mathrm{s}, \mathrm{H}-19), 0.93(3 \mathrm{H}, \mathrm{d}, J=6.8 \mathrm{~Hz}, \mathrm{H}-21)$, $0.87(3 \mathrm{H}, \mathrm{t}, J=7.6 \mathrm{~Hz}, \mathrm{H}-29), 0.86(3 \mathrm{H}, \mathrm{d}, J=6.8$ 
$\mathrm{Hz}, \mathrm{H}-26), 0.84(3 \mathrm{H}, \mathrm{d}, J=6.0 \mathrm{~Hz}, \mathrm{H}-27), 0.73(3 \mathrm{H}$, $\mathrm{s}, \mathrm{H}-18)$.

Caffeic acid (MV-3b): Yellowish amorphous solid; ${ }^{1} \mathrm{H}$ NMR (400 MHz, $\left.\mathrm{CDCl}_{3}\right): \delta 7.61(1 \mathrm{H}, \mathrm{d}, J$ $=16.0 \mathrm{~Hz}, \mathrm{H}-7), 7.09(1 \mathrm{H}, \mathrm{dd}, J=8.0,1.6 \mathrm{~Hz}, \mathrm{H}-6)$, $7.06(1 \mathrm{H}, \mathrm{d}, J=1.6 \mathrm{~Hz}, \mathrm{H}-2), 6.93(1 \mathrm{H}, \mathrm{d}, J=8.0 \mathrm{~Hz}$, H-5), $6.32(1 \mathrm{H}, \mathrm{d}, J=16.0 \mathrm{~Hz}, \mathrm{H}-8)$.

\section{RESULTS AND DISCUSSION}

After repeated chromatographic separation and purification of dichloromethane extract of the stem bark of M. velutina, we obtained four compounds (Figure 1). The isolated compounds were characterized by analysis of their high-resolution ${ }^{1} \mathrm{H}$ NMR spectroscopic data and comparison with published values.

The ${ }^{1} \mathrm{H}$ NMR spectrum (400 MHz, $\mathrm{CDCl}_{3}$ ) of compound MV-1 showed eight methyl group signals at $\delta 1.20,1.07,1.03,1.02,0.97,0.90,0.89$ and 0.75 . These were attributed to Me-17, Me-13, Me-14, Me$20 \alpha$, Me-20 $\beta$, Me-4, Me-9 and Me-5, respectively. A ketonic moiety rather alcoholic functional group was

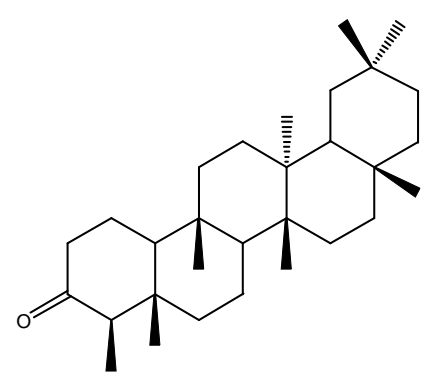

MV-1 (Friedelin)

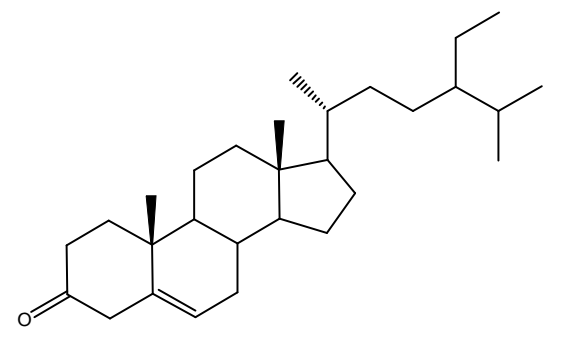

at C-3 position was affirmed by the absence of peak of oxymethine proton resonance around $\delta$ 3.0-3.5. These and other spectral characteristics shown in the material and method section are consistent with that reported for fridelin. ${ }^{21}$ Thus, MV-1 was identified as fridelin, which was substantiated by co-TLC with the authentic sample.

The ${ }^{1} \mathrm{H}$ NMR spectrum (400 $\mathrm{MHz}, \mathrm{CDCl}_{3}$ ) of compound MV-2 displayed a double doublet ( $\mathrm{J}=11.2$, $7.2 \mathrm{~Hz})$ at $\delta 3.21$, which can be assigned to the oxymethine proton, $\mathrm{H}-3$ in the triterpene nucleus. The spectrum also demonstrated the presence of six tertiary methyl groups at $\delta 1.05(\mathrm{H}-26), 0.99(\mathrm{H}-23)$, $0.97(\mathrm{H}-27), 0.85(\mathrm{H}-25), 0.81(\mathrm{H}-28)$ and $0.78(\mathrm{H}-$ $24)$. The multiplet of one proton intensity at $\delta 2.40$ was assigned to $\mathrm{H}-19$. An isopropenyl side chain with signals at $\delta 1.70(3 \mathrm{H}, \mathrm{s}, \mathrm{H}-30)$ and two olefinic protons at $\delta 4.59$ and $4.71(1 \mathrm{H}$, br. $\mathrm{s}$ each) demonstrates its relationship with lupane-type triterpenoids. The above spectral data are comparable to those published for lupeol. ${ }^{22,23}$ Based on these data, the identity of MV-2 was ascertained as lupeol.
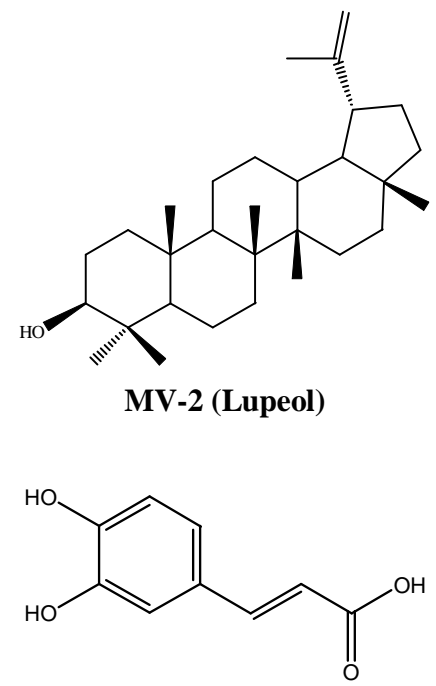

MV-3b (Caffeic acid)

MV-3a ( $\beta$-sitosterone)

Figure 1. Compounds MV-1, MV-2, MV-3a and MV-3b isolated from M. velutina.

The ${ }^{1} \mathrm{H}$ NMR spectrum (400 $\mathrm{MHz}, \mathrm{CDCl}_{3}$ ) of compound MV-3 revealed a mixture of two compounds, i.e. $\beta$-sitosterone or sitost-6-en-3-one
(MV-3a) and caffeic acid or 3,4-dihydroxy-transcinnamic acid (MV-3b). The signals attributable to MV-3a revealed a broad singlet at $\delta 5.75$ for the 
olefinic proton, $\mathrm{H}-6$ of the steroidal nucleus ${ }^{21}$ and six methyl signals at $1.20(3 \mathrm{H}, \mathrm{s}, \mathrm{H}-19), 0.93(3 \mathrm{H}, \mathrm{d}, J=$ $6.8 \mathrm{~Hz}, \mathrm{H}-21), 0.87(3 \mathrm{H}, \mathrm{t}, J=7.6 \mathrm{~Hz}, \mathrm{H}-29), 0.86$ $(3 \mathrm{H}, \mathrm{d}, J=6.8 \mathrm{~Hz}, \mathrm{H}-26), 0.84(3 \mathrm{H}, \mathrm{d}, J=6.0 \mathrm{~Hz}, \mathrm{H}-$ 27), $0.73(3 \mathrm{H}, \mathrm{s}, \mathrm{H}-18)$. The spectral characteristics of MV-3a are in close agreement to those observed for $\beta$-sitosterone or sitost-6-en-3-one. ${ }^{21}$

The ${ }^{1} \mathrm{H}$ NMR spectral signals assignable to the second compound MV-3b displayed a broad singlet at $\delta 7.06(\mathrm{H}-2)$ and two doublets $(J=8.0 \mathrm{~Hz})$ centered at $\delta 6.93$ (H-5) and 7.09 (H-6), each integrating for one proton indicated a 1,3,4trisubstituted aromatic moiety in compound MV-3b. Two downfield doublets at $\delta 7.61(1 \mathrm{H}, J=16.0 \mathrm{~Hz})$ and $6.32(1 \mathrm{H}, J=16.0 \mathrm{~Hz})$ revealed the presence of a pair of trans-coupled olefinic protons at $\mathrm{H}-7$ and $\mathrm{H}-8$, respectively. The above spectral features are in close agreement to those observed for caffeic acid ${ }^{21,24}$ and thus MV-3b was characterized as caffeic acid. Its identity was further confirmed by co-TLC with previously isolated sample.

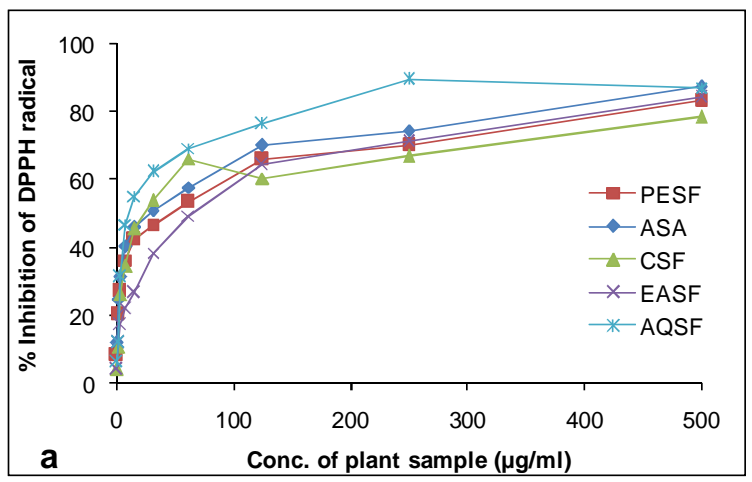

Figure 2. Concentration-dependent $\%$ inhibitions of DPPH radical scavenging activity (a) and $\mathrm{IC}_{50}$ of DEMV, PESF, CSF, EASF, AQSF and standard ASA (b).

Brine shrimp (Artemia salina) lethality bioassay is a common technique employed for preliminary toxicity screening of plant extracts. ${ }^{17} \mathrm{We}$ used percentage of shrimps died of the toxic effect of the samples in the $\mathrm{Y}$ axis, and the logarithmic values of concentrations in the $\mathrm{X}$ axis to plot the desired curve. We sketched the best-fit line to calculate the lethal concentration $\left(\mathrm{LC}_{90}\right)$ values of the test materials by

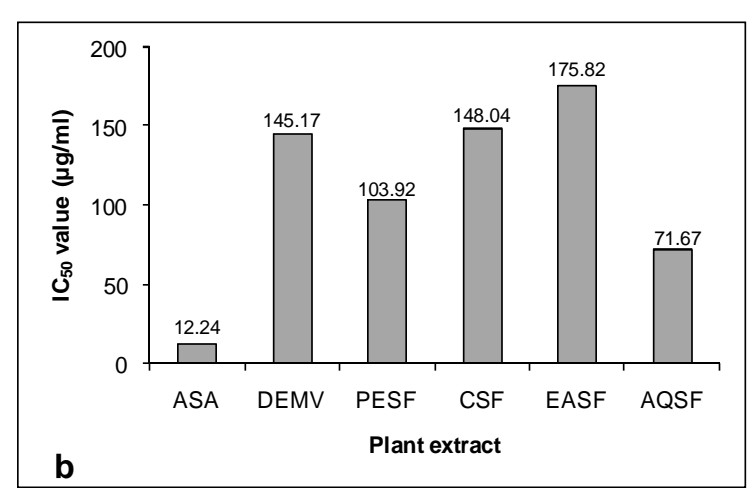

The DPPH radical scavenging assay is one of the most widely used method to evaluate the antioxidant potentials of plant extracts. Therefore, this method was employed to assess the antioxidant potential of M. velutina stem bark extractives via measuring the DPPH free radical scavenging ability. The results of antioxidant activity summarized in Figure 2 showed the concentration-dependent percentage inhibition of DPPH radical (Figure 2a) and $\mathrm{IC}_{50}$ values of DEMV, PESF, CSF, EASF, AQSF and standard at different concentrations (Figure 2b). M. velutina showed a significant antioxidant property that can be compared with the standard ASA at different concentrations tested. The percentage of DPPH scavenging activity of the tested plant samples increased with concentrations. As shown in Figure 2b, among all the extracts tested, AQSF of M. velutina showed the highest DPPH scavenging activity with $\mathrm{IC}_{50}$ values of $71.67 \mu \mathrm{g} / \mathrm{ml}$ followed by PESF. The DPPH scavenging activity of stem bark extract of $M$. velutina indicates that the stem bark may contain various active substances especially polyphenol with antioxidant activity. ${ }^{25}$

doing regression analysis. Compared to standard vincristine sulfate, all the test samples showed the significant brine shrimp larvicidal activity. The EASF exhibited the maximum $\mathrm{LC}_{90}$ values of $9.01 \mu \mathrm{g} / \mathrm{ml}$ which was more potent cytotoxic than vincristine sulfate $\left(\mathrm{LC}_{90}\right.$ of $\left.10.48 \mu \mathrm{g} / \mathrm{ml}\right)$. The second highest cytotoxic extract was the DEMV $\left(\mathrm{LC}_{90}=13.18\right.$ $\mu \mathrm{g} / \mathrm{ml}$ ), that was also significant compared to 
reference drug. Moreover, the other three plant samples CSF, AQSF and PESF showed noticeable $\mathrm{LC}_{90}$ values as $22.32,27.00$ and $36.45 \mu \mathrm{g} / \mathrm{ml}$, respectively (Table 1). The cytotoxic activity exhibited by the plant samples was promising and this clearly indicated the presence of potent bioactive compounds in the extract which requires further investigation. ${ }^{26}$

Table 1. Cytotoxic and thrombolytic activities of crude extract and different partitionates of $M$. velutina.

\begin{tabular}{ccc}
\hline Sample code & $\mathrm{LC}_{90}(\mu \mathrm{g} / \mathrm{ml})$ & \% Lysis of clot \\
\hline DEMV & 13.18 & 46.27 \\
PESF & 36.45 & 39.42 \\
CSF & 22.32 & 36.81 \\
EASF & 9.01 & 38.13 \\
AQSF & 27.00 & 36.68 \\
VS & 10.48 & -- \\
SK & -- & 68.68 \\
\hline
\end{tabular}

Here, DEMV = Dichloromethane crude extract of stem bark of $M$. velutina, $\mathrm{PESF}=$ Petroleum ether soluble fraction, $\mathrm{CSF}=$ Chloroform soluble fraction, EASF $=$ Ethyl acetate soluble fraction and $\mathrm{AQSF}=$ Aqueous soluble fractions, $\mathrm{VS}=$ Vincristine sulfate, SK $=$ Streptokinase

The thrombolytic activity of the dichloromethane extract of M. velutina and its different Kupchan fractions (PESF, CSF, EASF and AQSF) was assessed to screen its cardio protective potentiality. The anti-thrombus property of the plant samples has been expressed as $\%$ of clot lysis that is represented in Table 1. In this experiment, the addition of $100 \mu \mathrm{l}$ of 3000 I.U. streptokinase exhibited $68.68 \%$ lysis of blood clot after $90 \mathrm{~min}$ incubation at $37^{\circ} \mathrm{C}$. The negative control (distilled water) showed very negligible \% clot lysis $(0.12 \%)$. In this study, the DEMV exhibited highest thrombolytic activity (46.27\%) followed by PESF (39.42\%) and EASF $(38.13 \%)$. This might be an important finding which might have important implications in cardiovascular health.

With fewer adverse effects, plant-based extracted samples may have promising antimicrobial properties. Therefore, the development of antimicrobial agents from plant sources is an ongoing research interest globally. ${ }^{27}$ In this study, the crude dichloromethane extract of stem bark of M. velutina and its organic fractions, at $400 \mu \mathrm{g} / \mathrm{disc}$, were tested for antimicrobial screening using the disc diffusion method. ${ }^{19,20}$ The observed zone of inhibition of the tested samples ranged from 9 to $15 \mathrm{~mm}$ and 9 to 13 $\mathrm{mm}$ in antibacterial and antifungal assay, respectively (Table 2).

Table 2. Antimicrobial activities of different partitionates of M. velutina.

\begin{tabular}{lcccc}
\hline \multirow{2}{*}{ Test microorganisms } & \multicolumn{3}{c}{ Diameter of zone of inhibition $(\mathrm{mm})$} \\
\cline { 2 - 5 } Bacteria & PESF & CSF & AQSF & Standard \\
Eschericha coli & 9 & -- & Ciprofloxacin \\
Pseudomonas aeruginosa & 10 & 12 & 10 & 48 \\
Sarcina lutea & 10 & 10 & 10 & 48 \\
Shigella boydii & 11 & 15 & 11 & 49 \\
Sh. dysenteriae & -- & 10 & -- & 47 \\
Staphylococcus aureus & 9 & -- & 9 & 50 \\
Fungus & & & & 50 \\
Aspergillus niger & 9 & 9 & -- & Fluconazole \\
Candida albicans & 10 & 10 & 10 & 46 \\
Saccharomyces cerevisiae & 13 & 10 & 10 & 46 \\
\hline
\end{tabular}

Among the extractives, the PESF, CSF, and AQSF exhibited mild to moderate antimicrobial activity (Table 2). The CSF revealed the highest inhibition against the growth of tested microbes having a zone of inhibition ranged from $9 \mathrm{~mm}$ to $15 \mathrm{~mm}$ with maximum activity against Shigella boydii (zone of 
inhibition $=15 \mathrm{~mm}$ ). The findings of this study indicate that different samples of $M$. velutina have mild to moderate antimicrobial potential to inhibit the growth of different tested microbial strains.

\section{CONCLUSION}

The phytochemical analysis of the dichloromethane extract of the stem barks of $M$. velutina afforded four compounds, which were identified as friedelin, lupeol, $\beta$-sitosterone and caffeic acid. The results of in vitro pharmacological studies indicated that the tested samples of $M$. velutina have notable antioxidant, cytotoxic, thrombolytic, and moderate antimicrobial activities. In any case, it is vital to investigate the bioactive metabolites responsible for these pharmacological activities. The bioactivities of the extractives of $M$. velutina, as shown in our study, endorse the utilizations of this plant in the traditional system of medicine.

\section{REFERENCES}

1. Cragg, G.M. and Newman, D.J. 2013. Natural products: a continuing source of novel drug leads. Biochim. Biophys. Acta. 1830, 3670-3695.

2. Aguilar, G. 2001. Access to genetic resources and protection of traditional knowledge in the territories of indigenous peoples. Environ. Sci. Policy. 4, 241-256.

3. Jumana, S., Hasan, C.M. and Rashid, M.A. 2000. Alkaloids from the stem bark of Miliusa velutina. Biochem. Sys. Ecol. 28, 483-485.

4. Menon, M.K. and Kar, A. 1970. Analgesic effect of the essential oil of Miliusa tomentosa (Roxb.). Indian J. Exp. Biol. 8, 151-152.

5. Harrigan, G.G., Gunatilaka, A.A., Kingston, D.G., Chan, G.W. and Johnson, R.K. 1994. Isolation of bioactive and other oxoaporphine alkaloids from two annonaceous plants, Xylopia aethiopica and Miliusa cf. banacea. J. Nat. Prod. 57, 68-73.

6. Jumana, S., Hasan, C.M. and Rashid, M.A. 2000. Antibacterial activity and cytotoxicity of Miliusa velutina. Fitoterapia 71, 559-561.

7. Hasan, C.M., Jumana, S. and Rashid, M.A. 2006. (+)Isocorydine $\alpha-N$-oxide: A new aporphine alkaloid from Miliusa velutina. Nat. Prod. Lett. 14, 393-397.

8. Promgool, T., Kanokmedhakul, K., Tontapha, S., Amornkitbamrung, V., Tongpim, S., Jamjan, W. and Kanokmedhakul, S. 2019. Bioactive homogentisic acid derivatives from fruits and flowers of Miliusa velutina. Fitoterapia 134, 65-72.
9. Wongsa, N., Kanokmedhakul, K., Boonmak, J., Youngme, S. and Kanokmedhakul, S. 2017. Bicyclic lactones and racemic mixtures of dimeric styrylpyrones from the leaves of Miliusa velutina. RSC Adv. 7, 25285-25297.

10. Noman, M.A., Jamshidi, S., Ahsan, M., Hossain, T., Hasan, C.M. and Rahman, K.M. 2018. Crispene F and G, two new cis-clerodane furanoditerpenes isolated from Tinospora crispa, inhibit STAT3 dimerization. J. Nat. Prod. 81, 236242.

11. Arif, M., Kuddus, M.R., Islam, M.T. and Ibrahim, M. 2019. Evaluation of in vivo and in vitro biological activities of Gardenia latifolia Ait leaf. GSC Biol. Pharm. Sci. 7, 116123.

12. Kuddus, M.R., Rumi, F., Kaisar, M.A., Rahman, M.S., Hasan, C.M., Hassan, M.A. and Rashid, M. A. 2011. Secondary metabolites from Melocanna baccifera. Asian J. Chem. 23, 85-88.

13. VanWagenen, B.C., Larsen, R., Cardellina, J.H., Randazzo, D., Lidert, Z.C. and Swithenbank, C.1993. Ulosantoin, a potent insecticide from the sponge Ulosa ruetzleri. J. Org. Chem. 58, 335-337.

14. Pelletier, S.W., Chokshi, H.P. and Desai, H.K. 1986. Separation of diterpenoid mixtures using vaccum liquid chromatography. J. Nat. Prod. 49, 892-900.

15. Brand-willium, W., Cuvelier, M.E. and Berset, C. 1995. Use of free radical method to evaluate antioxidant activity. Lebensm Wiss Technol. 28, 25-30.

16. Meyer, B.N., Ferrigni, N.R., Putnam, J.E., Jacobsen, L.B., Nichols, D.E. and McLaughlin, J.L. 1982. Brine shrimp: a convenient general bioassay for active plant constituents. Planta. Med. 45, 31-34.

17. Apu, A.S., Muhit, M.A., Tareq, S.M., Pathan, A.H., Jamaluddin, A.T.M. and Ahmed, M. 2010. Antimicrobial activity and brine shrimp lethality bioassay of the leaves extract of Dillenia indica Linn. J. Young. Pharm. 2, 50-53.

18. Prasad, S., Kashyap, R.S., Deopujari, J.Y., Purohit, H.J., Taori, G.M. and Daginawala, H.F. 2006. Development of an in vitro model to study clot lysis activity of thrombolytic drugs. Thrombosis J. 4, 14.

19. Bauer, A.W., Kirby, W.M.M., Sherris, J.C. and Turck, M. 1966. Antibiotic susceptibility testing by standardized single disc method. Am. J. Clin. Pathol. 36, 493-496.

20. Bhalodia, N.R. and Shukla, V. J. 2011. Antibacterial and antifungal activities from leaf extracts of Cassia fistula I.: An ethnomedicinal plant. J. Adv. Pharm. Technol. Res. 2, 104109.

21. Begum, F., Haque, M.R., Nahar, K.S. and Rashid, M.A. 2014. Secondary metabolites from different extractives of Stereospermum suaveolens. Dhaka Univ. J. Pharm. Sci. 13, 31-36.

22. Rahman, M.S., Faisal, A., Hasan, C.M., Ahsan, M. and Masud, M.M. 2017. Chemical and biological investigations of Cerbera odollam Gaertn. Dhaka Univ. J. Pharm. Sci.16, 179-186. 
23. Rafe, M.R., Ahsan, M., Hasan, C.M. and Masud, M.M. 2017. Chemical and biological studies of leaf extract of Dendrophthoe falcata Linn. Dhaka Univ. J. Pharm. Sci. 16, 215-219.

24. Kuddus, M.R., Rumi, F., Kaisar, M.A. and Hasan, C.M. 2010. Sesquiterpene and phenylpropanoids from Curcuma longa. Bangladesh Pharm. J. 13, 31-34

25. Tantary, S., Masood, A., Bhat, A.H., Dar, K.B., Zargar, MA. And Ganie, S. A. 2017. In vitro antioxidant and RBC membrane stabilization activity of Euphorbia wallichii. Free Rad. Antiox.7, 13-22.
26. Ullah, M.O., Haque, M. and Urmi, K.F., et al. 2013. Antibacterial activity and brine shrimp lethality bioassay of methanolic extracts of fourteen different edible vegetables from Bangladesh. Asian Pac. J. Trop. Biomed. 3,1-7.

27. Oikeh, E.I., Omoregie, E.S., Oviasogie, F.E. andOriakhi, K. 2015. Phytochemical, antimicrobial, and antioxidant activities of different citrus juice concentrates. Food Sci. Nutr. 4, 103-109. 